\title{
Biofunctional Sr-and Si-loaded titania nanotube coating of Ti surfaces by anodization-hydrothermal process
}

This article was published in the following Dove Press journal: International Journal of Nanomedicine

\author{
Yong Huang ${ }^{1, *}$ \\ Xue Shen ${ }^{2, *}$ \\ Haixia Qiao' \\ Hao Yang ${ }^{3}$ \\ Xuejiao Zhang' \\ Yiyao Liu ${ }^{2}$ \\ Hejie Yang ${ }^{4}$ \\ 'College of Lab Medicine, Hebei \\ North University, Zhangjiakou, \\ ${ }^{2}$ School of Life Science and \\ Technology, University of Electronic \\ Science and Technology of China, \\ Chengdu, ${ }^{3}$ Key Laboratory for \\ Green Chemical Process of Ministry \\ of Education, Wuhan Institute of \\ Technology, Wuhan, ${ }^{4}$ State Key \\ Laboratory for Mechanical Behavior \\ of Materials, Xi'an Jiaotong University, \\ Xi'an, China \\ *These authors contributed equally \\ to this work
}

Correspondence: Haixia Qiao

College of Lab Medicine, Hebei North University, I I Diamond South Road,

Zhangjiakou 075000, China

Tel +86 3134029270

Email haixiaqiao@yeah.net

Yiyao Liu

School of Life Science and Technology,

University of Electronic Science and

Technology of China, Number 4

of Section 2, Jianshe North Road,

Chengdu, Sichuan 610054, China

Tel +862883203353

Fax +8628 83208238

Email liuyiyao@uestc.edu.cn
Background: Two frequent problems associated with titanium (Ti) surfaces of bone/dental implants are their corrosion and lack of native tissue integration.

Methods: Here, we present an anodization-hydrothermal method for coating Ti surfaces with a layer of silicon ( $\mathrm{Si}$ )- and strontium ( $\mathrm{Sr}$ )-loaded titania nanotubes (TNs). The Ti surfaces coated with such a layer ( $\mathrm{Si}-\mathrm{Sr}-\mathrm{TNs})$ were characterized with different techniques.

Results: The results indicate that the $\mathrm{Si}^{4+}$ and $\mathrm{Sr}^{2+}$ ions were evenly incorporated into the TNs and that the $\mathrm{Si}-\mathrm{Sr}$-TN layer provides good protection against corrosive media like simulated body fluid. The excellent cytocompatibility of the coating was confirmed in vitro by the significant growth and differentiation of MC3T3-E1 osteoblastic cells.

Conclusion: Being easily and economically fabricated, the Si-Sr-TN surfaces may find their niche in clinical applications, thanks to their excellent biological activity and corrosion resistance.

Keywords: $\mathrm{TiO}_{2}$ nanotube, silicon, strontium, cytocompatibility, corrosion resistance

\section{Introduction}

The high corrosion resistance of titanium (Ti) results from the growth of a protective titanium dioxide $\left(\mathrm{TiO}_{2}\right)$ film on its surface (2-6 nm thickness). ${ }^{1}$ However, this nanothick passive layer is not inert to corrosive attack when subjected to aggressive biological conditions (eg, $\mathrm{pH}$ variation, presence of fluorides, and surface wear). ${ }^{2}$ The intrinsic bioinertness of Ti surfaces and its alloys usually results in poor osseointegration due to insufficient bone formation, which then increases the risk of instability after surgical procedures. ${ }^{3}$ The osseointegrative potential of commercial pure Ti surfaces has recently been enhanced through tuning their wettability, chemistry, and nanotopography. ${ }^{4}$ One of such approaches is to cover Ti surfaces with a coating of anodic titania nanotubes (TNs), which effectively promotes bone formation, ${ }^{4,5}$ a highly ordered TN array with lateral dimensions $<100 \mathrm{~nm}$ was formed on the surface of a Ti substrate anodized in fluoride-containing electrolytes. ${ }^{6,7}$

Nanostructured surfaces provide an opportunity to more closely resemble the surface topography of living tissue. It has been shown that $\mathrm{TiO}_{2}$ nanotube (NT) arrays clearly accelerate apatite formation and, moreover, transformation from amorphous into the crystalline $\mathrm{TiO}_{2}$ facilitates this process. ${ }^{8-10}$ From cell in vitro studies, it has become increasingly evident that surface morphology can influence cell fates. A mechanism is driven by promoting the adsorption of selected proteins (such as fibronectin and vitronectin), which are important for mediating signals between the 
cell, the material surface, and the cell adhesion. ${ }^{11}$ Additionally, NTs with open volume nanotubular structures have been shown to be ideal carriers for drug loading and release. ${ }^{12}$ NTs have great potential as a long-term drug delivery system because they provide a novel and effective strategy by adding bioactive agents to raise implantation success rates. The osteogenic activity of Ti surfaces has been improved through incorporating different elements such as strontium $(\mathrm{Sr})$ and silicon $(\mathrm{Si})$ into the NTs. ${ }^{13}$ These ions play important roles in the adhesion, growth, and differentiation of osteogenic cells and also in osteoclastogenesis and bone resorption. Si-doped TNs significantly enhance the expression of the genes involved in the osteogenic differentiation; ${ }^{14}$ the incorporation of $\mathrm{Sr}$ into the TNs has improved the initial adhesion, migration, and differentiation of preosteoblast cells; ${ }^{3}$ therefore, it can be conjectured that the $\mathrm{Sr} / \mathrm{Si}$ codoping of the TNs may synergistically enhance their osteoblast proliferation and differentiation as compared to the separate loading of $\mathrm{Sr}$ or $\mathrm{Si}^{15}{ }^{15}$ However, $\mathrm{Sr}-\mathrm{Si}$-codoped $\mathrm{TiO}_{2} \mathrm{NTs}$ ' formation on Ti under anodization-hydrothermal condition has not been yet extensively studied. Being easily and economically fabricated, the Si-Sr-TN surfaces may find their niche in clinical applications, thanks to their excellent biological activity and corrosion resistance.

Therefore, the present work is aimed at demonstrating that the simultaneous incorporation of Si and Sr into the TNs can significantly enhance the corrosion resistance of TN-coated Ti substrates and can ultimately stimulate the bone formation around such $\mathrm{Sr}-\mathrm{Si}$-codoped TN-coated Ti implants. We here report on the anodization-hydrothermal synthesis of $\mathrm{Sr}-\mathrm{Si}$ codoped TN (Si-Sr-TNs) layers and their morphological, physicochemical, and electrochemical characterization. The biological response of the $\mathrm{Si}-\mathrm{Sr}-\mathrm{TN}$ layers has also been understood by exploring the cellular adhesion, cell proliferation, and osteogenic differentiation marker. Figure 1 shows the schematic process for the preparation and characterization of the highly ordered arrays of $\mathrm{Si}-\mathrm{Sr}-\mathrm{TNs}$ on $\mathrm{Ti}$.

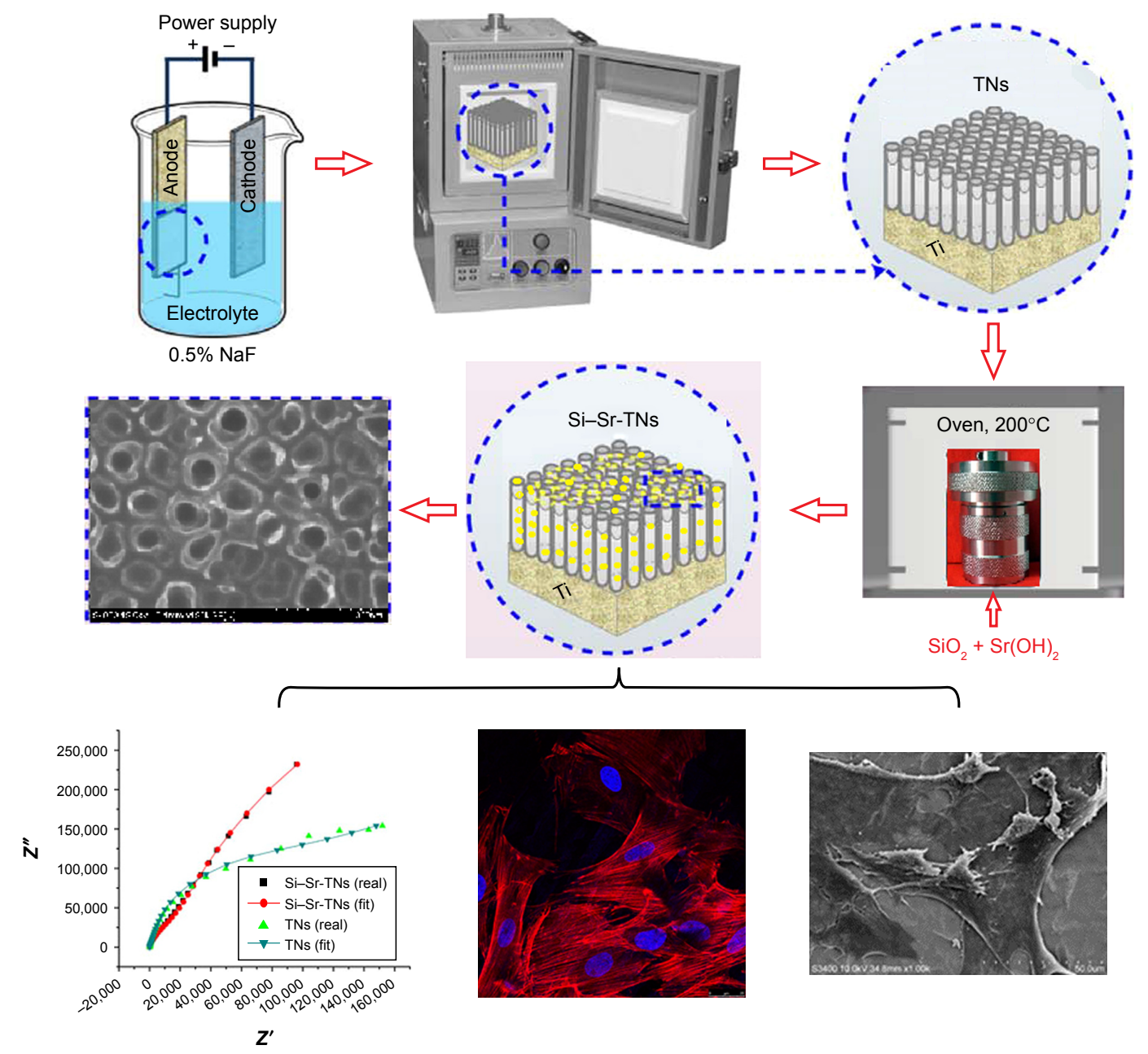

Figure I Schematic process for the preparation and characterization of the highly ordered arrays of Si-Sr-TNs on titanium. Abbreviations: $\mathrm{Si}$, silicon; $\mathrm{Sr}$, strontium; TNs, titania nanotubes. 


\section{Experimental details}

The TNs were fabricated from commercially pure Ti foils ( $99.9 \%$ purity, $10 \times 10 \times 1 \mathrm{~mm}$; Non-Ferrous Metals, Ltd, Baoji, China) using the anodization process. ${ }^{16,17}$ The TN arrays were prepared by the standard two-electrode anodization at room temperature in the potentiostatic mode. The cathode was a platinum plate, and the anode was the Ti sample. To create the NT layers, the samples were anodized in an electrolyte containing $0.5 \mathrm{wt} \%$ of hydrogen fluoride solution. The anodizing voltage was kept at $20 \mathrm{~V}$ during the $50 \mathrm{~min}$ process. After the anodization, the samples were sintered at $450^{\circ} \mathrm{C}$ for $2 \mathrm{~h}$. The purpose of the heat treatment was to enhance the crystallinity of the hydroxyapatite coating and to make the TNs transform from amorphous to anatase phase. Analytical-grade Sr hydroxide and nano-silicon dioxide $\left(\mathrm{SiO}_{2}\right)$ were adopted as the sources for $\mathrm{Sr}$ and $\mathrm{Si}$, respectively. All reagents were purchased from Aladdin Ltd, Shanghai, China. The hydrothermal solution consisted of $1 \mathrm{~g} / \mathrm{L}$ nano- $\mathrm{SiO}_{2}(15 \pm 5 \mathrm{~nm})$ and $0.02 \mathrm{M} \mathrm{Sr}(\mathrm{OH})_{2}(\mathrm{pH}=12.4)$. The anodized samples were then hydrothermally treated for $4 \mathrm{~h}$ at $200^{\circ} \mathrm{C}$ in a $25 \mathrm{~mL}$ Teflon-lined autoclave to fabricate the $\mathrm{Si}-\mathrm{Sr}-\mathrm{TN}$ layers. Then, the samples were rinsed with $0.1 \mathrm{M} \mathrm{HCl}$ to eliminate the residual $\mathrm{Sr}(\mathrm{OH})_{2}$.

We characterized the surface topography of the SiSr-TN samples using a field-emission scanning electron microscopy (JSM-7500F; JEOL) and analyzed their crystalline structure with X-ray diffraction (XRD) (D/Max-2500; Rigaku); their surface chemical compositions were analyzed with X-ray photoelectron spectroscopy (XPS) (ESCALAB
250XI; Thermo Fisher Scientific, Waltham, MA, USA) and energy-dispersive X-ray spectrometer (Max20 EDAX); the wettability was measured with a contact angle meter (DSA 100; Kruess, Hamburg, Germany). ${ }^{16}$ The electrochemical measurement process was explained elsewhere. ${ }^{17}$

The MC3T3-E1 mouse preosteoblasts (Cell Bank of Chinese Academy of Sciences, Shanghai, China) were incubated at $37^{\circ} \mathrm{C}$ in a $5 \% \mathrm{CO}_{2}$ environment in $\alpha$-minimum essential medium with $10 \%$ fetal bovine serum and $1 \%$ streptomycin/ penicillin. We conducted a cell-counting kit-8 (CCK-8) assay with MC3T3-E1 cells to identify potential cellular toxicity of the $\mathrm{Si}-\mathrm{Sr}-\mathrm{TN}$ samples after 7 days were passed since the seeding of the cells onto the sample. ${ }^{3}$ In addition, the preosteoblasts $\left(8 \times 10^{4}\right.$ cells/well $)$ were seeded onto the surface of the Si-Sr-TN samples in a 24-well plate and were then incubated for 1 day to allow cell adhesion. Thereafter, the unattached cells were removed through gentle washing with phosphate-buffered saline at $37^{\circ} \mathrm{C}$; then, the adhering cells were immersed in a $4 \%$ paraformaldehyde solution for $10 \mathrm{~min}$ and were then stained using phalloidin ( $5 \mu \mathrm{g} / \mathrm{mL}$; Sigma-Aldrich Co., St Louis, MO, USA) and 4',6-diamidino-2-phenylindole. Fluorescence images of the adhering cells were obtained by a stereomicroscope (model SMZ745/745T; Nikon Corporation, Tokyo, Japan) (for the details on the assay processes of cell morphology and alkaline phosphatase [ALP] activity, refer Huang et a ${ }^{16,17}$ ).

\section{Results and discussion}

As shown in Figure 2A and C, the $\mathrm{Si}-\mathrm{Sr}-\mathrm{TNs}$ and the TN samples exhibited tubular nanostructures with an average
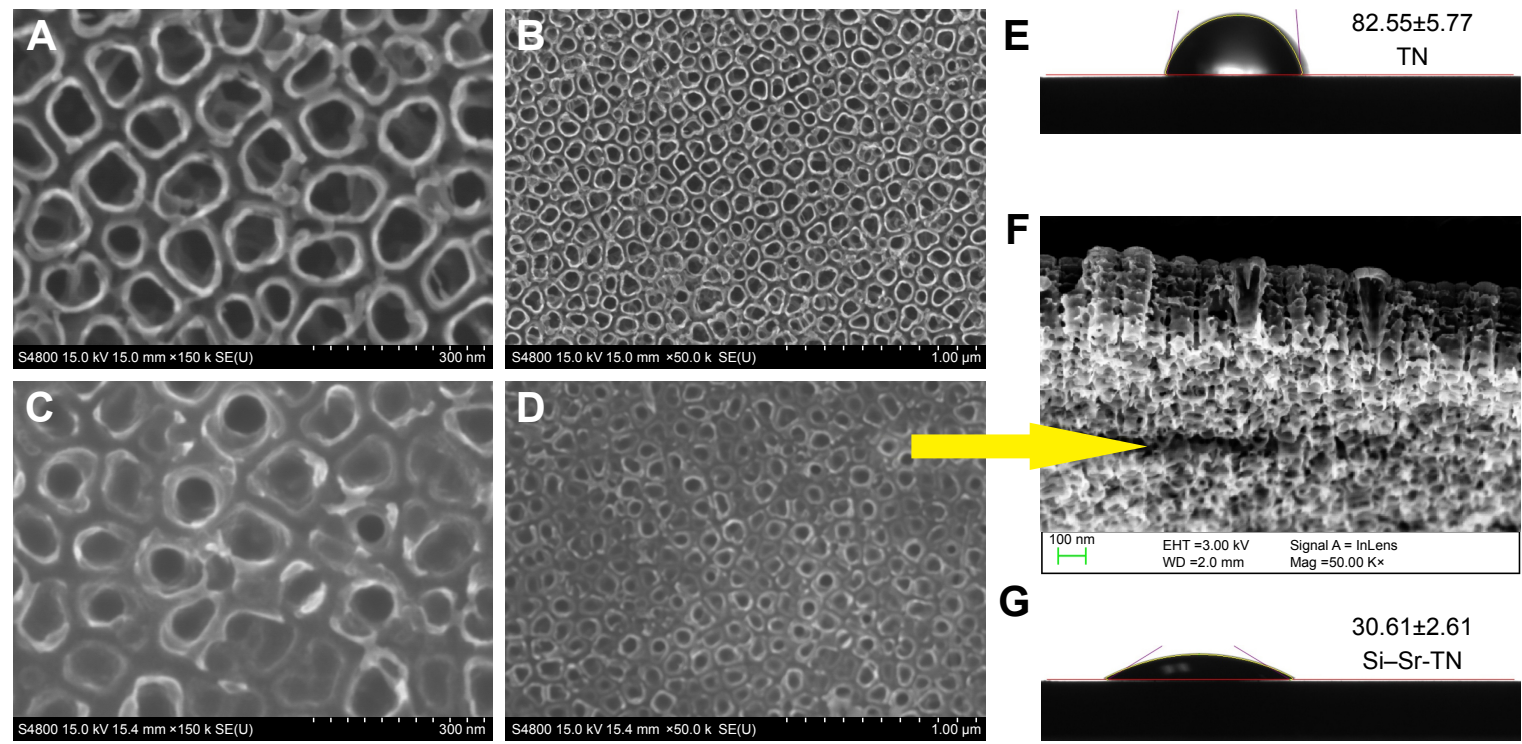

Figure 2 The water droplet images and the contact angle values of $(\mathbf{E})$ the TNs and $(\mathbf{G})$ the Si-Sr-TNs and the FESEM images of the TNs $(\mathbf{A}$ and $\mathbf{B})$ and the Si-Sr-TNs (C and D). Cross-section morphology of the Si-Sr-TNs (F).

Abbreviations: FESEM, field-emission scanning electron microscopy; Si, silicon; Sr, strontium; TN, titania nanotube.

International Journal of Nanomedicine 2018:13

submit your 
inner diameter of 50 and $100 \mathrm{~nm}$ and the average wall thickness of the NTs is 15 and $50 \mathrm{~nm}$, respectively. The total thickness of the NT layer is $\sim 300 \mathrm{~nm}$ (Figure 2F). The closepacked arrangement of the NT in the Si-Sr-TN layers (eg, Figure 2D) is denser and smoother than that of the TN samples represented in Figure 2B. As shown in Figure 2E and G, the $\mathrm{TN}$ samples exhibit a high contact angle of $82.55^{\circ} \pm 5.77^{\circ}$; the doped $\mathrm{Si}$ and $\mathrm{Sr}$ give rise to a considerably lower contact angle of $30.61^{\circ} \pm 2.61^{\circ}$ for the $\mathrm{Si}-\mathrm{Sr}-\mathrm{TN}$ sample; the abundant hydrophilic hydroxyl-terminated groups on the surfaces of the $\mathrm{Si}-\mathrm{Sr}-\mathrm{TN}$ sample give rise to hydrophilicity, making it favorable for cell attachment and proliferation. ${ }^{18}$

The energy-dispersive spectroscopy (EDS) patterns of the $\mathrm{Si}-\mathrm{Sr}-\mathrm{TNs}$ (Figure 3A) shown in Figure 3B indicate that the $\mathrm{Si}-\mathrm{Sr}-\mathrm{TNs}$ are mainly composed of $\mathrm{Sr}, \mathrm{Si}, \mathrm{O}$, and $\mathrm{Ti}$; the $\mathrm{O}$ and $\mathrm{Ti}$ amounts are primarily due to the $\mathrm{TNs}$; the presence of $\mathrm{Si}$ and $\mathrm{Sr}$ suggests that the $\mathrm{Si}$ and $\mathrm{Sr}$ had been doped into the TNs; the amounts of the incorporated $\mathrm{Si}$ and $\mathrm{Sr}$ were found to be -3.57 and $3.60 \mathrm{wt} \%$, respectively. Figure $3 \mathrm{C}$ reflects the uniform distribution of $\mathrm{O}, \mathrm{Si}, \mathrm{Sr}$, and $\mathrm{Ti}$ across the coating surface.

The peak located at $35^{\circ}$ of the XRD patterns of the $\mathrm{Si}-\mathrm{Sr}$ TNs, given in Figure 4A, can be attributed to cubic $\mathrm{SrTiO}_{3}$, which indicates that the $\mathrm{TiO}_{2}$ in the NTs has partly been converted into $\mathrm{SrTiO}_{3}$ during the hydrothermal process; ${ }^{3}$ moreover, there are peaks in the spectrum that have originated from anatase $\mathrm{TiO}_{2}$ and the $\mathrm{Ti}$ substrate. The full XPS of the $\mathrm{Si}-\mathrm{Sr}-\mathrm{TNs}$, given in Figure 4B, confirms that the $\mathrm{Sr}-\mathrm{Si}-\mathrm{TN}$ coating layers consisted of $\mathrm{Si}, \mathrm{Ti}, \mathrm{O}$, and $\mathrm{Sr}$. The fine XPS spectrum of $\mathrm{Sr} 3 \mathrm{~d}$ in the $\mathrm{Si}-\mathrm{Sr}-\mathrm{TN}$ includes two peaks at 134.6 and $136.7 \mathrm{eV}$ that are assigned to $\mathrm{Sr} 3 \mathrm{~d} 5 / 2$ and $\mathrm{Sr} 3 \mathrm{~d} 3 / 2$, respectively; therefore, the $\mathrm{Sr}$ in the TNs is in the form of $\mathrm{SrTiO}_{3}$. The fine XPS peaks of $\mathrm{Si} 2 \mathrm{p}$ and $\mathrm{Si} 2 \mathrm{~s}$, which have been measured at 368.3 and $374.3 \mathrm{eV}$, respectively, confirm that the deposits within the $\mathrm{SrTiO}_{3} \mathrm{NT}$ array consist of $\mathrm{SiO}_{2}$ and $\mathrm{Sr}_{2} \mathrm{SiO}_{4}$, which was consistent with the EDS analysis.

Despite the high corrosion resistance of Ti materials, they are not inert to corrosive attack in the presence of the aggressive biological environment. ${ }^{19}$ Thus, the study of how $\mathrm{Si}-\mathrm{Sr}-\mathrm{TNs}$ behave when submitted to corrosive conditions is of upmost importance. ${ }^{20}$ Figure $4 \mathrm{C}$ shows that the $\mathrm{Si}-\mathrm{Sr}-\mathrm{TNs}$ exhibit better corrosion resistance than the TN samples. The nanoporous surface of the TNs gives rise to a high corrosion current density $\left(i_{\text {corr }}\right)$ for the TN sample. The results summarized in the inserted table (Figure 4C) indicate that the incorporation of $\mathrm{Si}$ and $\mathrm{Sr}$ has improved the corrosion resistance of the TN samples, which is in line with the findings of Ahmadi et al. ${ }^{21}$ As shown in Figure 4D, the Nyquist plots of the TN and $\mathrm{Si}-\mathrm{Sr}-\mathrm{TN}$ samples indicate that the latter have larger capacitive loops than the former. As the loop radius increases, the corrosion resistance can be enhanced because of higher impedance values. $^{22}$ The same conclusion can be drawn through a
A

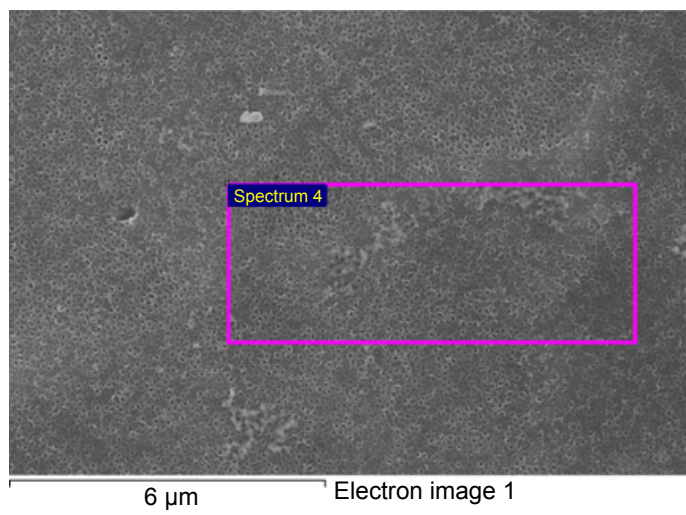

B

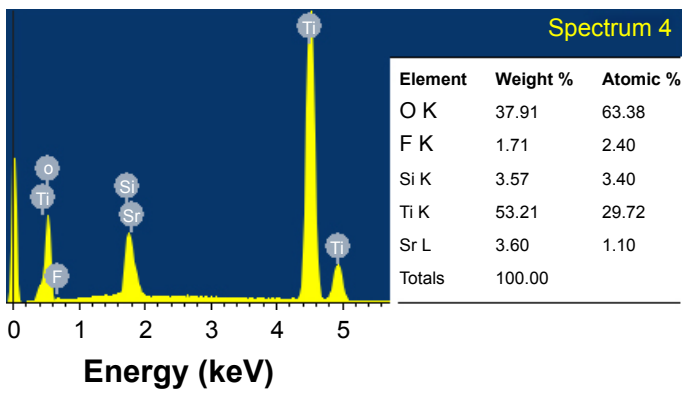

C
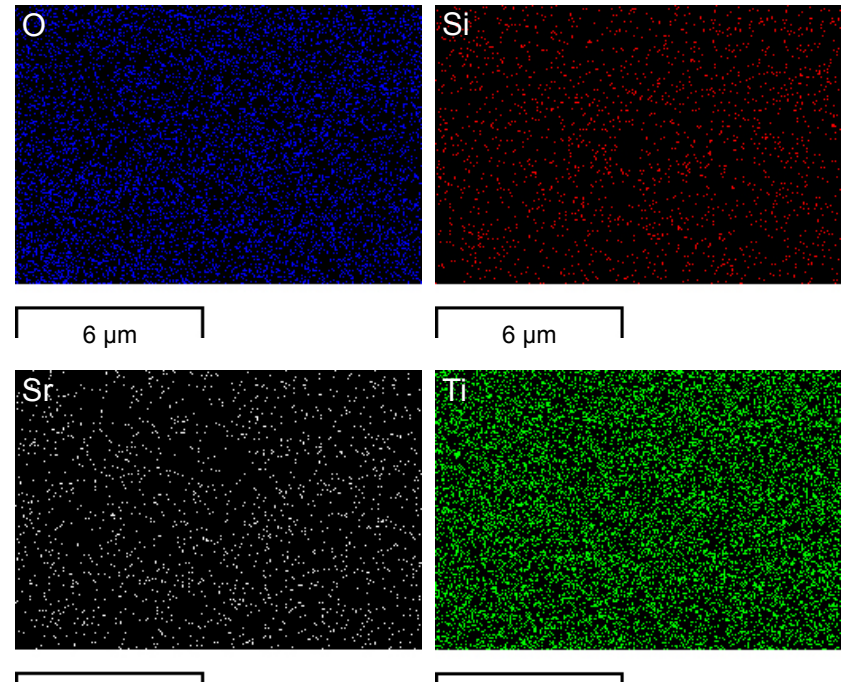

$6 \mu \mathrm{m}$

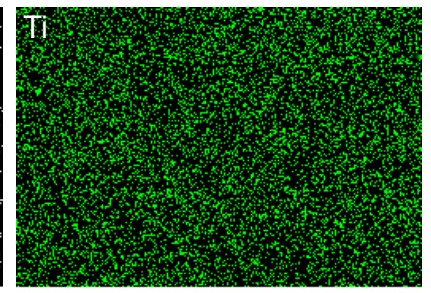

$6 \mu \mathrm{m}$

Figure 3 The FESEM images of the Si-Sr-TNs (A), the EDS elemental spectrum (B), and EDS mapping spectrum (C) of the Si-Sr-TNs.

Abbreviations: EDS, energy-dispersive spectroscopy; FESEM, field-emission scanning electron microscopy; Si, silicon; Sr, strontium; TNs, titania nanotubes. 
A
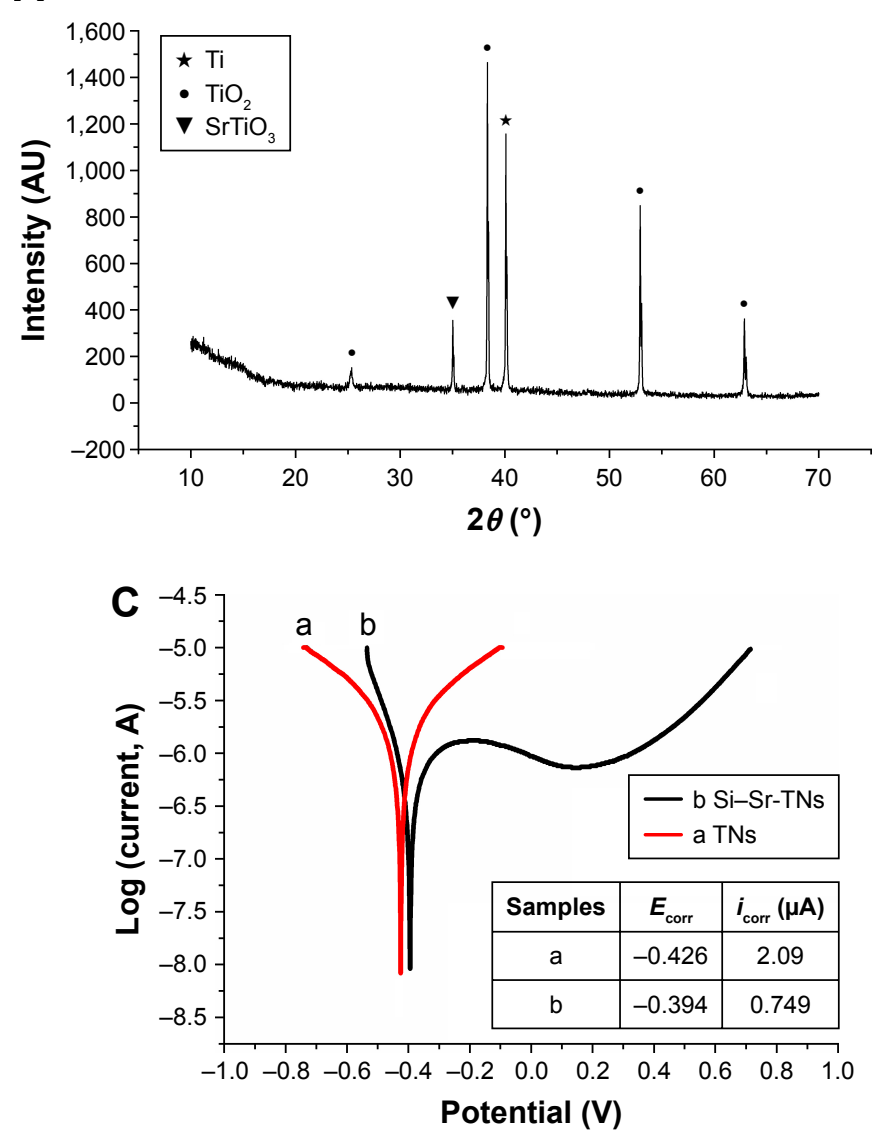
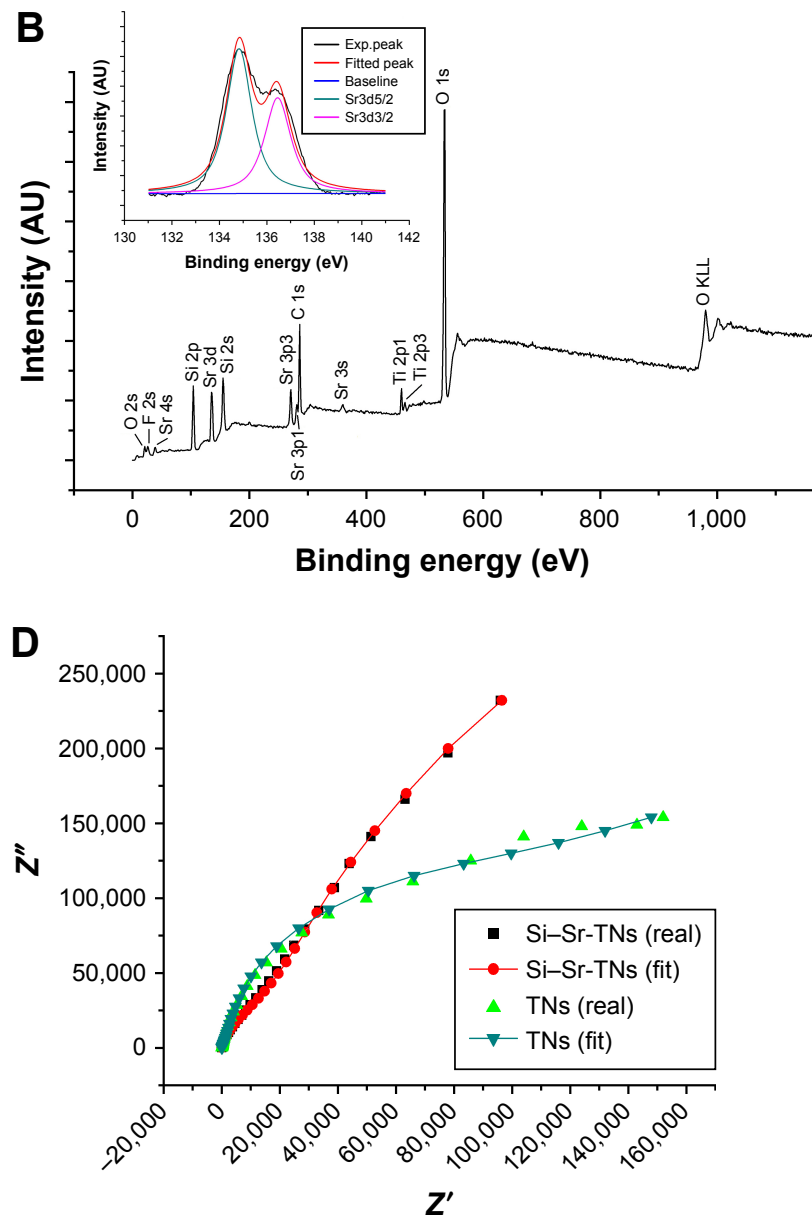

Figure 4 (A) The XRD pattern of the Si-Sr-TNs, (B) the XPS general spectrum of the Si-Sr-TNs, (C) the Tafel polarization curves of the TNs and Si-Sr-TNs, (D) the experimental and fitted Nyquist plots of the TNs and Si-Sr-TNs. The results here belong to only one sample, though we did many measurements on many samples. The parameters $E_{\text {corr }}$ and $i_{\text {corr }}$ stand for the corrosion potential and the corrosion current density, respectively.

Abbreviations: Exp, experimental; Si, silicon; Sr, strontium; TNs, titania nanotubes; XPS, X-ray photoelectron spectroscopy; XRD, X-ray diffraction.

qualitative comparison between the polarization data and the Nyquist plots. It is known that implant surface features significantly influence the electrochemical stability of the metallic implant when in contact with simulated body fluids. Very interestingly, in particular, $\mathrm{TiO}_{2}$ NTs have also shown potential to prevent long-term implant failure due to biocorrosion. ${ }^{23}$ In general, both the nanotubular surfaces display a fast and effective passivation behavior, which may be related to the properties of the barrier layer formed at $\mathrm{TN}$ interfaces during the anodization process. ${ }^{24}$ The same trend was observed by Grotberg et $\mathrm{a}^{23}$ for NTs grown from Ti6Al4V substrates. $\mathrm{Yu}$ et $\mathrm{al}^{25}$ also studied the corrosion behavior of $\mathrm{TiO}_{2} \mathrm{NT}$ layers in Hank's solution, and they concluded that the Ipass density was significantly influenced by Ti oxide NTs grown by anodization. Electrochemical impedance spectroscopy results confirmed the better corrosion resistance of TNs because of a thicker barrier layer present on nanotubular films than on smooth Ti. From electrochemical impedance spectroscopy and potentiodynamic studies, the authors concluded that very low corrosion current densities were recorded on $\mathrm{TiO}_{2}$ NTs due to a strong passive oxide film formation. ${ }^{26}$ However, after $\mathrm{Sr}$ and Si enrichment of NT surfaces by anodization-hydrothermal processes, significantly lower $i_{\text {corr }}$ values were found for Si-Sr-TN samples (Figure 4C), suggesting that they display superior corrosion resistance ability. The characterization of the newly formed TN interfaces after hydrothermal method of NTs in $\mathrm{Sr} / \mathrm{Si}$ electrolyte regarding compact layer morphology, thickness, and elemental composition is of upmost importance. This knowledge will allow to predict the mechanisms behind the barrier layer formation and to understand the properties responsible for the improved corrosion resistance of $\mathrm{Sr} / \mathrm{Si}$-doped $\mathrm{TiO}_{2} \mathrm{NTs}$. The enhanced corrosion resistance provides a relatively stable environment for better initial cell attachment and the ensuing cell growth.

The immunofluorescence images given in Figure 5A-F reveal the cytoskeletal actin of cells, which indicate that the 

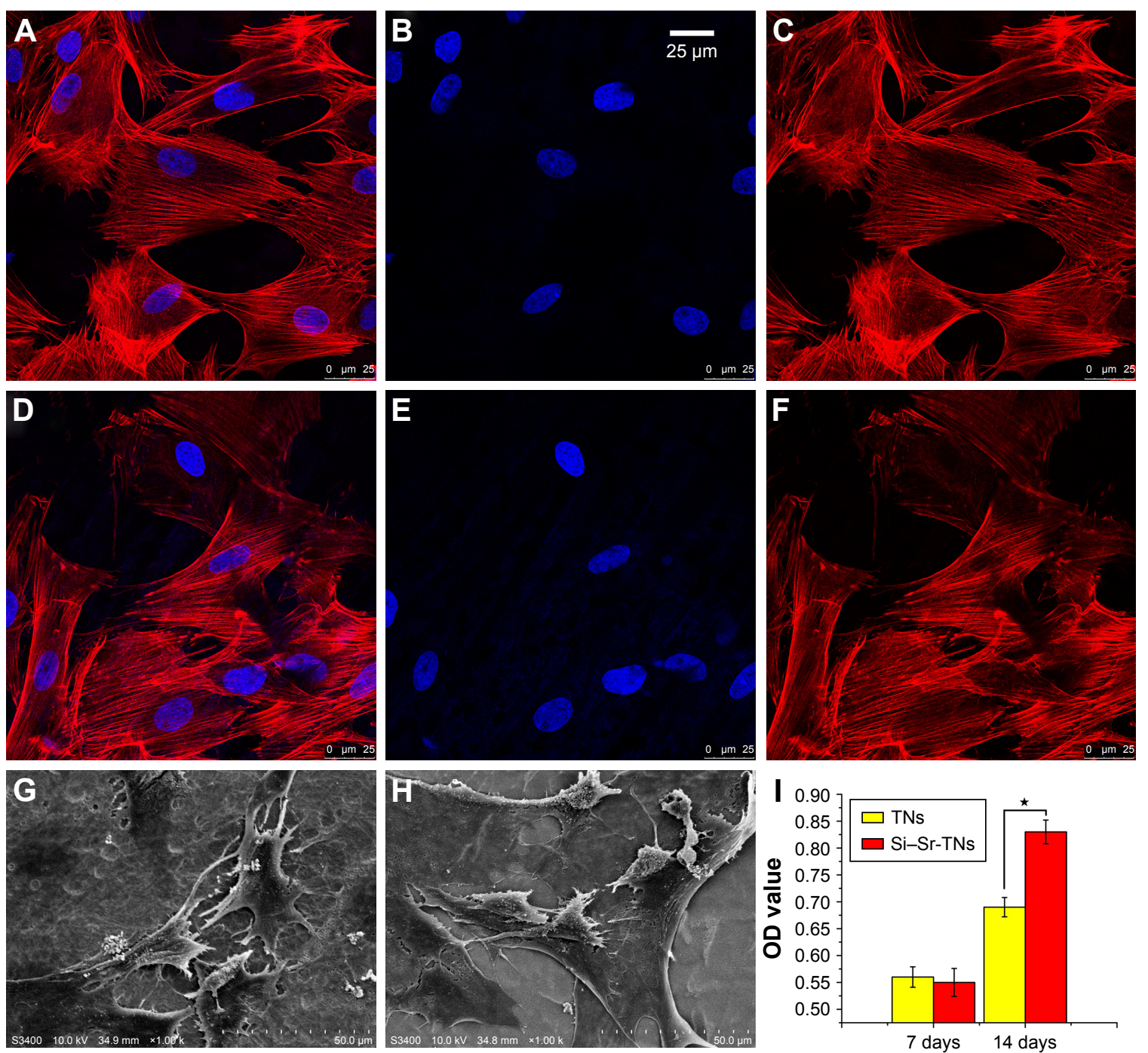

Figure $\mathbf{5}$ The confocal microscopic fluorescent images of cells that were immunostained for F-actin (red) and nuclei (blue) after being cultured on the TNs (A-C) and the Si-Sr-TNs (D-F) for $24 \mathrm{~h}$. The scanning electron microscopy images of the morphology of the cells cultured on the TNs (G) and the Si-Sr-TNs (H) for $24 \mathrm{~h}$. (I) The ALP activity of the osteoblasts cultured on the TNs and the Si-Sr-TNs in 7 and 14 days $\left({ }^{\star} P<0.05\right)$.

Abbreviations: ALP, alkaline phosphatase; OD, optical density; Si, silicon; Sr, strontium; TNs, titania nanotubes.

number of adhered cells did not significantly differ after culturing for 1 day; there is even no obvious difference between the cytoskeletons of the TN and Si-Sr-TN samples; that is, all the cells were polygonal and well distributed. Figure $5 \mathrm{G}$ and $\mathrm{H}$ demonstrates the cellular attachment behavior on the surfaces of the TNs and the Si-Sr-TNs, respectively. The resulted morphologies are not very distinct - the MC3T3-E1 cells are flat and actively spread with a number of filopodia protrusions, which reflect a normal cell attachment and growing process. ${ }^{27}$

The proliferation of MC3T3-E1 cells cultured on the TNs and $\mathrm{Si}-\mathrm{Sr}-\mathrm{TNs}$ was measured by CCK- 8 assay; the data have not been presented here; no significant difference in both of the sample groups was observed, suggesting that cellular toxicity is not a concern. Figure 5I illustrates the activity of the ALP in the cells on the surface of the TN and the Si-Sr-TN samples; the amount of the ALP increased with increasing the cell incubation time - after 14 days of incubation, the amount of the ALP in the Si-Sr-TNs was much higher than that in the TNs. In conclusion, the MC3T3-E1 cells could keep their typical osteoblastic morphology on the $\mathrm{Si}-\mathrm{Sr}-\mathrm{TNs}$ surface, which is an indication of its minimal cytotoxicity. Furthermore, the released mineral ions such as $\mathrm{Sr}$ and $\mathrm{Si}$ from the $\mathrm{Si}-\mathrm{Sr}$-TNs can promote the osteoblast differentiation. According to Lin et al, ${ }^{15}$ the codoping of the functional elements like $\mathrm{Si} / \mathrm{Sr}$ may be of considerable use in designing osteogenic and angiogenic bioactive materials for bone regeneration. 


\section{Conclusion}

For the first time, through anodization, Ti implant surfaces were coated with TN arrays, which were then loaded with $\mathrm{Si}$ and $\mathrm{Sr}$ by a hydrothermal treatment. Through in vitro electrochemical measurements, we have learned that the corrosion resistance of the $\mathrm{Si}-\mathrm{Sr}-\mathrm{TN}$-coated $\mathrm{Ti}$ surfaces is superior to that of the TN-coated surfaces of Ti. Both types of coatings have been found to possess similar cytoskeleton and morphology, that is, the trace $\mathrm{Si}$ and $\mathrm{Sr}$ doping did not change the proliferation of osteoblasts (MC3T3-E1). However, the codoping has improved the osteoblasts' differentiation, for the ALP secretion has been increased. Being easily and economically fabricated, the $\mathrm{Si}-\mathrm{Sr}-\mathrm{TN}$ surfaces may find their niche in clinical applications, thanks to their excellent biological activity and corrosion resistance.

\section{Acknowledgment}

This work was supported by the Second Batch of Young Talents Fund of Hebei Province, China, the Natural Science Foundation of Hebei Province, China (number H2016405008), the Youth Fund of Science and Technology of Hebei Colleges, China (QN2017010), the Population Health Information in Hebei Province Engineering Technology Research Center, the Science and Technology Research Project of Zhangjiakou, China (17120012D), and the Medical Science Research Project Planning Project of Health and Family Planning Commission of Hebei Province (2018).

\section{Disclosure}

The authors report no conflicts of interest in this work.

\section{References}

1. Yang L, Chinthapenta V, Li Q, et al. Understanding osteoblast responses to stiff nanotopographies through experiments and computational simulations. J Biomed Mater Res A. 2011;97(4):375-382.

2. Mathew MT, Abbey S, Hallab NJ, Hall DJ, Sukotjo C, Wimmer MA Influence of $\mathrm{pH}$ on the tribocorrosion behavior of $\mathrm{CpTi}$ in the oral environment: synergistic interactions of wear and corrosion. J Biomed Mater Res B Appl Biomater. 2012;100(6):1662-1671.

3. Cheng H, Xiong W, Fang Z, et al. Strontium (Sr) and silver (Ag) loaded nanotubular structures with combined osteoinductive and antimicrobial activities. Acta Biomater. 2016;31:388-400.

4. Minagar S, Li Y, Berndt CC, Wen C. The influence of titania-zirconiazirconium titanate nanotube characteristics on osteoblast cell adhesion. Acta Biomater. 2015;12:281-289.

5. Lin X, Yang SF, Lai K, et al. Orthopedic implant biomaterials with both osteogenic and anti-infection 3 capacities and associated in vivo evaluation methods. Nanomedicine. 2017;13(1):123-142.

6. Macak JM, Tsuchiya H, Ghicov A, et al. $\mathrm{TiO}_{2}$ nanotubes: self-organized electrochemical formation, properties and applications. Curr Opin Solid State Mater Sci. 2007;11(1-2):3-18.

7. Lee K, Mazare A, Schmuki P. One-dimensional titanium dioxide nanomaterials: nanotubes. Chem Rev. 2014;114(19):9385-9454.
8. Cipriano AF, Miller C, Liu H. Anodic growth and biomedical applications of TiO nanotubes. J Biomed Nanotechnol. 2014;10(10):2977-3003.

9. Indira K, Kamachi Mudali U, Rajendran N. In-vitro biocompatibility and corrosion resistance of strontium incorporated $\mathrm{TiO}_{2}$ nanotube arrays for orthopaedic applications. J Biomater Appl. 2014;29(1): $113-129$.

10. Xin YC, Jiang J, Huo KF, Hu T, Chu PK. Bioactive $\mathrm{SrTiO}_{3}$ nanotube arrays: strontium delivery platform on Ti-based osteoporotic bone implants. ACS Nano. 2009;3(10):3228-3234.

11. Zhong S, Luo RF, Wang X, et al. Effects of polydopamine functionalized titanium dioxide nanotubes on endothelial cell and smooth muscle cell. Colloids Surf B Biointerfaces. 2014;116:553-560.

12. Zhang YX, Dong CF, Yang SF, et al. Alkalescent nanotube films on a titanium-based implant: a novel approach to enhance biocompatibility. Mater Sci Eng C Mater Biol Appl. 2017;72:464-471.

13. Khudhair D, Bhatti A, Li Y, et al. Anodization parameters influencing the morphology and electrical properties of $\mathrm{TiO}_{2}$ nanotubes for living cell interfacing and investigations. Mater Sci Eng C. 2016;59: 1125-1142.

14. Zhao XJ, Wang T, Qian S, Liu XY, Sun JY, Li B. Silicon-doped titanium dioxide nanotubes promoted bone formation on titanium implants. Int J Mol Sci. 2016;17(3):292-304.

15. Lin KL, Wang XH, Zhang N, Shen YH. Strontium (Sr) strengthens the silicon ( $\mathrm{Si}$ ) upon osteoblast proliferation, osteogenic differentiation and angiogenic factor expression. J Mater Chem B. 2016;4:3632-3638.

16. Huang Y, Xu ZW, Zhang XJ, et al. Nanotube-formed Ti substrates coated with silicate/silver co-doped hydroxyapatite as prospective materials for bone implants. J Alloy Compd. 2017;697:182-199.

17. Huang Y, Zhang XJ, Zhang HL, et al. Fabrication of silver- and strontiumdoped hydroxyapatite $/ \mathrm{TiO}_{2}$ nanotube bilayer coatings for enhancing bactericidal effect and osteoinductivity. Ceram Int. 2017;43(1 pt B): 992-1007.

18. Bakhsheshi-Rad HR, Hamzah E, Ismail AF, et al. Novel bi-layered nanostructured $\mathrm{SiO}_{2} / \mathrm{Ag}$-FHAp coating on biodegradable magnesium alloy for biomedical applications. Ceram Int. 2016;42(10):11941-11950.

19. Jayaraman M, Meyer U, Bühner M, Joos U, Wiesmann HP. Influence of titanium surfaces on attachment of osteoblast-like cells in vitro. Biomaterials. 2004;25(4):625-631.

20. Alves SA, Patel SB, Sukotjo C, et al. Synthesis of calcium-phosphorous doped $\mathrm{TiO}_{2}$ nanotubes by anodization and reverse polarization: a promising strategy for an efficient biofunctional implant surface. Appl Surf Sci. 2017;399:682-701.

21. Ahmadi S, Mohammadi I, Sadrnezhaad SK. Hydroxyapatite based and anodic titania nanotube biocomposite coatings: fabrication, characterization and electrochemical behavior. Surf Coat Technol. 2016; 287:67-75.

22. Roman I, Trusca RD, Soare ML, et al. Titanium dioxide nanotube films: preparation, characterization and electrochemical biosensitivity towards alkaline phosphatase. Mater Sci Eng C. 2014;37:374-382.

23. Grotberg J, Hamlekhan A, Butt A, et al. Thermally oxidized titania nanotubes enhance the corrosion resistance of Ti6A14V. Mater Sci Eng C. 2016;59:677-689.

24. Monsees TK, Barth K, Tippelt S, et al. Effects of different titanium alloys and nanosize surface patterning on adhesion, differentiation, and orientation of osteoblast-like cells. Cells Tissues Organs. 2005; 180(2):81-95.

25. Yu Wq, Qiu J, Xu L, Zhang Fq. Corrosion behaviors of $\mathrm{TiO}_{2}$ nanotube layers on titanium in Hank's solution. Biomed Mater. 2009;4(6): 065012 .

26. Yu X, Li Y, Wlodarski W, Kandasamy S, Kalantar-zadeh K. Fabrication of nanostructured $\mathrm{TiO}_{2}$ by anodization: a comparison between electrolytes and substrates. Sens Actuators B Chem. 2008;130(1):25-31.

27. Kim SY, Kim YK, Jang YS, et al. Bioactive effect of alkali-heat treated $\mathrm{TiO}_{2}$ nanotubes by water or acid treatment. Surf Coat Technol. 2016;303(Prt A):256-267. 


\section{Publish your work in this journal}

The International Journal of Nanomedicine is an international, peerreviewed journal focusing on the application of nanotechnology in diagnostics, therapeutics, and drug delivery systems throughout the biomedical field. This journal is indexed on PubMed Central, MedLine, CAS, SciSearch ${ }^{\circledR}$, Current Contents ${ }^{\circledR} /$ Clinical Medicine,

Journal Citation Reports/Science Edition, EMBase, Scopus and the Elsevier Bibliographic databases. The manuscript management system is completely online and includes a very quick and fair peer-review system, which is all easy to use. Visit http://www.dovepress.com/ testimonials.php to read real quotes from published authors.

Submit your manuscript here: http://www.dovepress.com/international-journal-of-nanomedicine-journal 